\title{
Ethikprobleme von Unternehmen in Rußland
}

Die heutige Lage der Wirtschaft in Rußland wird in vielem vom Fehlen einer zivilisierten Unternehmung bestimmt. Die Herrschaft der Kommandowirtschaft in den vergangenen Jahren schuf im Bewußtsein der überwiegenden Bevölkerung die Meinung, daß die russischen Unternehmer Gauner und Betrüger seien, die sowohl einander, als auch die ganze Bevölkerung zu betrügen pflegen. Die neu erschienenen russischen Unternehmer beweisen meistens die Gerechtigkeit einer solchen Auffassung. Das Fehlen der Rechtsgrundlage der Unternehmungsentwicklung in Rußland sowie die Herrschaft der neuen Prozesse bremsenden Bürokraten drängen die Unternehmer zu Handlungen, mit deren Hilfe sie möglich schnell viel Geld „abzwacken“ oder „abzapfen“ könnten, welches sie nicht in die Produktionserweiterung, sondern in Immobilien und Luxusgegenstände investieren.

Die entstehende Unternehmung wird auch von der Traditionslosigkeit des Liberalismus beeinflußt. Ohne den vernünftigen Gebrauch der Freiheit ist es unmöglich, ein zivilisiertes Unternehmungsmedium zu besitzen. Das Fehlen der harten staatlichen Wirtschaftskontrolle in der demokratischen Gesellschaft fordert ein hohes Rechtsbewußtsein und innerliche Ethikkultur. Es ist bekannt, daß der wichtigste Regler der Unternehmungsbeziehungen in den Ländern mit hochentwickelter Marktwirtschaft das Moralprinzip ist. Infolgedessen wird ein Ehrenwort unter den Unternehmern sehr hoch geschätzt. Zahlreiche Unternehmens-vereinigungen haben ihren eigenen berufsmäßigen Ehrenkodex, dem gemäß sie zusammenarbeiten. Bis jetzt sind viele russische Unternehmer der Meinung, daß die Ehre und andere Moralprinzipien nicht nützlich sind. Einer der kennzeichnenden Züge der Unternehmung in Rußland war vor einigen Jahren das Abenteuer. Allein in Wolgograd kann man zwei Unternehmungen nennen, die ihre Investoren betrogen haben.- „Russkij Dom Selenga“" und „Chopör“.

Nach unserer Auffassung wäre es zugleich falsch, alle neu erschienenen Unternehmer auf eine gleiche Stufe zu stellen. Die immer größere Zahl der Unternehmer ist bereit, von ihren Moralprinzipien ausgehend, die Spielregeln des zivilisierten Marktes aufzunehmen. Viele Firmen führen in ihrer Tätigkeit nach dem Vorbild der führenden Westunternehmen den Ehrenkodex ein.

Es schien uns, daß die Moralforderungen der Unternehmer der entwickelten Länder ein gutes Beispiel und Vorbild für russische Unternehmen sein können. Es gibt viele positive Beispiele der Erfahrungsaufgabe der zivilisierten Unternehmung durch die Tätigkeit der Zweiggeschäfte der westlichen Unternehmen, die auf dem russischen Markt handeln.

Juri Osadschij, Technische Universität Wolgograd 